$\left.\begin{array}{c}\text { gournals } \\ \text { ONTERNATIONAL JOURNAL OF } \\ \text { ORGANIZATIONAL LEADERSHIP }\end{array}\right) \begin{gathered}\text { INDUSTRIAL } \\ \text { MANAGEMENT } \\ \text { INSTITUTE }\end{gathered}$

\title{
The Role of Transformational Leader in Developing Knowledge Culture in Public Sector Hospitals
}

\author{
Sobia Mahmood ${ }^{1 *}$, Muhammad Arif Khattak ${ }^{2}$ \\ ${ }^{1} \mathrm{PhD}$ Scholar, Bahria University, Islamabad, Pakistan \\ ${ }^{2}$ Associate Professor, Bahria University, Islamabad, Pakistan
}

\begin{tabular}{|c|c|}
\hline & ABSTRACT \\
\hline \multicolumn{2}{|l|}{ Keywords: } \\
\hline $\begin{array}{l}\text { Transformational } \\
\text { Leadership, Knowledge } \\
\text { Sharing, Organizational } \\
\text { Culture, Trust }\end{array}$ & $\begin{array}{l}\text { The study emphasizes on the role of transformational leader in developing a culture of } \\
\text { knowledge sharing in public sector hospitals. Transformational leaders may become the } \\
\text { source of inspiration and serve as role models for organizational members to share their } \\
\text { valuable knowledge with others. The leaders are unable to develop an organizational }\end{array}$ \\
\hline $\begin{array}{l}\text { Received } \\
11 \text { November } 2016\end{array}$ & $\begin{array}{l}\text { culture where there is trust among organizational members to share their valued knowledge } \\
\text { with each other. However, it is needed to know that whether a cause and effect relationship }\end{array}$ \\
\hline $\begin{array}{l}\text { Received in revised form } \\
15 \text { December } 2017\end{array}$ & $\begin{array}{l}\text { exists among transformational leader and knowledge sharing. The implication of the } \\
\text { present study is the result of the dangerous nature of the problem that confronts not only }\end{array}$ \\
\hline $\begin{array}{l}\text { Accepted } \\
29 \text { December } 2017\end{array}$ & $\begin{array}{l}\text { some hospitals, but whole health sector and indeed countries as a whole. The present study } \\
\text { helps in developing a trust based organizational culture where employees feel free to share } \\
\text { their worthwhile knowledge. By sharing knowledge, the performance of the hospitals can }\end{array}$ \\
\hline & also be enhanced and patient care becomes easier. \\
\hline
\end{tabular}

Correspondence:

arifkhattak78@gmail.com

CAIMI Journals

The study concentrates on the role of transformational leader in developing a culture of knowledge sharing in public sector hospitals. The notion of transformational leaders may become the source of inspiration and serve as role models for organizational members to share their valuable knowledge with each other and create change in order to be innovative (Olson, Belohlav, Cook \& Hays, 2008). It is a worldwide dilemma where the organizational leadership is not able to maintain its valuable knowledge; as a result, the quality of services is reduced and ultimately, customers are dissatisfied around the globe particularly in developing countries. However, it may be needed to explore whether a cause and effect relationship exists between 
transformational leader and knowledge sharing. Nevertheless, it is intended to find out how these relationships support the enhancing performance of the hospitals.

A number of studies indicated leadership style may enhance knowledge sharing (Bryant, 2003). However, there has been little empirical evidence in the literature about the cause and effect relationships among leadership styles and knowledge sharing.

The transformational leadership influences others to create new ideas and that have a remarkable effect on individual's creativity within the organization (Oreg \& Berson, 2011). Further, they also stressed that it significantly enhances knowledge sharing in the corporate world. In developed and developing economies there may be in utmost need of the organizations to develop a trust based organizational culture where employees feel free to share their valuable knowledge with one another. By sharing knowledge, organizational intellectual capital can be managed and enhanced: Although it is one of the major resource that is not reflected in the balance sheet, but have significant impact on firm's overall productivity to add value (Edvinsson \& Sullivan, 1996). The knowledge sharing is an intangible asset of the organization and it must be utilized to increase the complete functioning and execution of the organization particularly in health care sector (Bate, \& Robert, 2002; Fletcher et al., 2003; Habersam \& Piber, 2003; Peng, Pike, \&Roos, 2007;).

The current study intends to explore the logical conjecture about the nature of the association among transformational leader and sharing of knowledge by following the positivist paradigm. To achieve the set objectives of the present study, the target population is individuals who are sharing their knowledge to enhance performance of the hospitals. An extensive review of literature in the context of health care sector in developed and developing economies indicated the top management is more concerned about employees' productivity (Cialdini, Petrova, Goldstein, \& Team, 2004). This goal oriented approach of top management impacts the knowledge sharing of an organization that resultantly affect the capacity building of the firm and ultimately affect the performance of the organization (Hussi, 2004). On the basis of this argument, the explicit problem statement of the present study is:

"To examine the role of transformational leader and knowledge sharing to improve the performance of health care sector in Pakistan"

It is also contended; how does the transformational leader impact the corporate organizational culture, trust, and sharing of knowledge (tacit and implicit) among individuals within the organization. Further, it is intended to determine the mediation of sharing of knowledge and how this conjecture affects the performance of the healthcare sector in Pakistan".

The dynamic and competitive environment may force the top management (organizational leadership) to satisfy the multiple needs of the stakeholders including customers, employees, and organization. The present study contributes towards the three categories of knowledge, namely research, policy practice, and theoretical knowledge. The implication of the present study is the result of the dangerous nature of the problem that confronts not only some hospitals, but whole health sector and indeed countries as a whole. The present study investigates the part of significance for individuals who may be concerned with evaluating the relationship of transformational leader with knowledge sharing and knowledge sharing with 
organizational performance in the healthcare sector, as it was known from the literature that it is a missing link that has to be filled in, by doing an empirical study.

The generalizability of the framework provides practical guidelines to the public healthcare sector of Pakistan to improve the performance of hospitals. The present study helps in organizing an essential component of a quality enhancement program, enhancing the efficiency of hospitals, and enhancing patient care. The current study investigates the public sector hospitals of Pakistan as of its emerging prominence and zero tolerance for mistakes. Public sector hospitals are confronting one of the largest problem that there is a deficiency of transformational leader who develops a trust based organizational culture where knowledge worker share their valuable knowledge with their peer colleagues in this regard. By sharing knowledge organizational functions and operations are improved.

\section{The Literature Review}

The intellectual context of the present study in terms of dominant and theoretical views for the discovery and advocacy of the main argument and then the discussion moves towards the problem statement. The contextual overview and its issues are also discussed in the light of the key argument in the present study. The first part of this section discusses the historical development of transformational leader and its dominant positions. These studies provide the basis for understanding the transformational leader and its relationship with knowledge sharing. This section ends with the question, why the leaders are unable to develop and create an organizational culture where employees do not feel hesitation in sharing their knowledge with others. This sharing of knowledge among individuals improves performance of the hospital.

An extensive review of literature specifies, the notion of transformational leadership was introduced in 1978 by James McGregor Burns and afterward it was continued by Bernard and his associates and co-workers (Avolio \& Bass, 2002; Avolio, Bass, \& Jung, 1999; Bass, 1985; Berson \& Avolio, 2004). They focused on examining leaders who transform groups, organizations, and even companies. These types of leadership style maintain and develop the behaviors and actions of their followers (Bass, 1999; Bass \& Riggio, 2006; Shamir, House, \& Arthur, 1993).

Leaders play a vital role in generating, handling, and utilizing knowledge within organizations (Bryant, 2003). By dealing with all these three stages of knowledge exploitation procedure, every business may achieve competitive advantage (Ribière \& Sitar, 2003). Burns (1978) recognized two types of leadership styles, namely transformational and transactional. A limited research studies have been done on the role of transformational and transactional leadership styles upon knowledge worker's functions and operations and organizational functions and operations by acquiring, creating, sharing, and exploiting knowledge (Bryant, 2003; Oreg \& Berson, 2011; Politis, 2001).

Savage (1996) has divided the wave of socio-economic development into three categories; first one refers to agriculture age in which wealth is defined as ownership of land; second is industrial age, in which wealth is defined as ownership of capital; and the third is knowledge age in which wealth is defined as possession of knowledge and the ability to utilize it for the betterment of product and services. 
Based on socioeconomic perspectives it might be argued that the driving forces behind the dynamic organizations are managing knowledge by their leaders. The better dissemination and management of knowledge may depend on the style of leadership. As suggested by a number of studies (Birasnav, Rangnekara, \& Dalpati, 2011), the utilization of individual's tacit and explicit knowledge within the organization significantly depends on transformational leader. Considering the views indicated in the era of knowledge based economy, there might be dare need of the organizations to cultivate a trust based organizational culture for augmenting knowledge sharing in service oriented organizations specifically health care sector to enhance their organizational functioning and operations (Benevene \& Cortini, 2010).

Organizational success depends more upon the workers to share their valuable knowledge and this is possible only when transformational leader articulates goals, builds image or provides a suitable model, and foster the compliance on group goals; following this, expectations of raised operations, personalized assistance, and creative and intellective inspiration are among factors which are of great importance. The transformational leader encourages opinions, emotions, and actions that are coherent with one another (Bass \& Avolio, 1994). It has a thorough command of the change waves (Eisenbach, Watson, \& Pillai, 1999) and transformational leader influences others to create new ideas and that have an amazing consequence on creativity. It is a kind of leadership which may enable the individuals to share their hidden capitals to expand their dynamic potentials within the organizations (Beugré, Acar, \& Braun, 2006).

An extensive review of the literature that indicated organizational performance particularly in service oriented organizations is critical for sustainable competitive edge. As Kenagy, Berwick, \& Shore (1999) demonstrated, most of the dynamic organizations in service sector are unable to maintain the performance at three levels of the firm including individuals, process, and organizational wide. Further, they argued that there are so many reasons organizations are unable to sustain their organizational performance. They identified a number of reasons and one of the key lacks is transformational leader and sharing of knowledge (tacit and implicit knowledge) and that may directly impact the organizational functioning and operations.

In the recent era, service oriented organizations particularly health care sector in Pakistan faces continuing pressure to improve organizational functioning and operations. The organizational functioning and operations have been a focus for the health care sector for some time. In other words, there is a need of uninterrupted improvement in service quality that is being delivered to the general public. Many private health care providers have turned toward organizational functioning and operations as a means of achieving better performance and patient satisfaction (Andaleeb, 2000; Cronin \& Taylor, 1992; Davies, Nutley, \& Mannion, 2000; Ferlie \& Shortell, 2001; Kenagy et al., 1999; Rosenthal \& Frank, 2006; Scotti, Harmon, \& Behson, 2006).

The organizational functioning and operations of health care have been neglected by health care providers in developing countries particularly in public sector (Rosenthal \& Frank, 2006; Scotti et al., 2007). The proponents predicted that poor organizational functioning and operations in the public sector hospitals led to greater use of private sector. In this regard, one of the major challenges for the health care providers is how to improve organizational 
functioning and operations, as the health related issues are amongst the utmost and noticeable factor of human fears (Andaleeb, 2001). Organizational performance may also be increased by developing an organizational culture where knowledge workers may share their worthwhile knowledge. An organizational culture is conceived as the nature of the firms and set norms beliefs, values shared by the individuals, and they act according to them within the organization (Middleton, 2002; Denison, 1990,1996).

The sharing and transmitting of knowledge with their connotations in numerous social networks help in the development of creating value for the organization (Argote, Ingram, Levine, \& Moreland, 2000; Haas, \& Hansen, 2007). The study of Chen \& Huang (2007) and Scott (2005) identified that social networks and relations formulate upraised communication and collaboration between knowledge workers. For creating networks and socializations, valuable and immense degree of trust amongst the knowledge workers is required. There is an utmost desire to formulate trust in an organization for the sharing of knowledge. Furthermore, collaboration, harmonization, and interaction between knowledge workers is needed. Social network and communication is required to formulate and nurture the knowledge sharing culture inside the organization (Dhanaraj, Lyles, Steensma, \&Tihanyi, 2004; Dixon, 2000; Hendriks, 1999; Orr, 1990).

An organizational leadership may establish the trust that could help the organization to achieve its business goals and store its valuable implicit and explicit knowledge (Ardichvili, Page, \& Wentling, 2003; Chen, 2004; Lee, Gillespie, Mann, \& Wearing, 2010). A number of studies argued that trust supports the augmenting of knowledge sharing (Renzl, 2008; Gressgård, 2011; Malhotra, 2002). Trustworthiness of a colleague is an ambiguous notion that is changing and that frequently changes by environmental changes and trust in leadership are very much critical as both of them facilitate knowledge sharing (Malhotra, 2002).

Based on these views, knowledge sharing might be contended within the organization depending upon trust; if the knowledge workers lack trust then they never want to share their valuable knowledge with their peer worker. Trust is one of the biggest hindrances in knowledge sharing and impact the intellectual ability of an individual within the organization. Trust among team members is the key element for enhancing knowledge sharing that facilitates in augmenting Intellectual Capital (Gressgård, 2011). Knowledge sharing is the most important factor (Choy, Lee, Cheung \& Shim, 2005) as when knowledge is shared easily in the organization it leads towards enhancing organizational functioning and operations which should be the ultimate aim of every organization particularly for health care sector (Ferlie \& Shortell, 2001).

The organizational performance of hospitals is basically satisfying patients in such a way that they feel their needs are fulfilled and they always want to come back. In developing countries this issue is more neglected as compared to developed countries as their first priority is health. It is evident that patient's satisfaction is always related with the quality. Organizational performance cannot be enhanced and maintained without achieving the satisfaction level of patients (Kenagy et al., 1999; Shaikh, \& Hatcher, 2005; Duygulu, \& Kublay, 2011).

Health care providers should focus on the factors that enhance performance of the hospitals to get back the confidence of their valuable patients (Lam, 1997; Munir et al., 2012). By taking 
such measures they might be able to satisfy the needs of their patients and the confidence of the patients will regain. For achieving extraordinary organizational performance, it is essential to build and manage knowledge sharing. The strategies and decisions taken by the leaders are one of the biggest hurdles in diminishing the worthwhile knowledge and transformational leader plays a vital role in developing an organizational culture where there is trust and knowledge workers feel free to share their knowledge (Bounfour \& Edvinsson, 2005; Jabnoun, \& Rasasi, 2005; Saint-Onge, 1996; Cassels, 1995). When knowledge of the organization is increased the organization is augmented, it leads towards increasing service quality.

\section{The Study}

\section{Theoretical Framework}

One of the desired outcomes of the present study is to measure the relationship among the transformational leader and knowledge sharing and to examine how transformational leader enhances knowledge sharing and also, it is aimed to measure the mediating role of trust and organizational culture in enhancing knowledge sharing. In this perspective, the present study aims to formulate a feasible predictive model that directs a complete study of the theoretically relevant components within the research. The model presented in the study may not claim to be a comprehensive model for the explanation of factors which contributes in enhancing knowledge sharing. Figure 1 presents the theoretical framework of the present study.

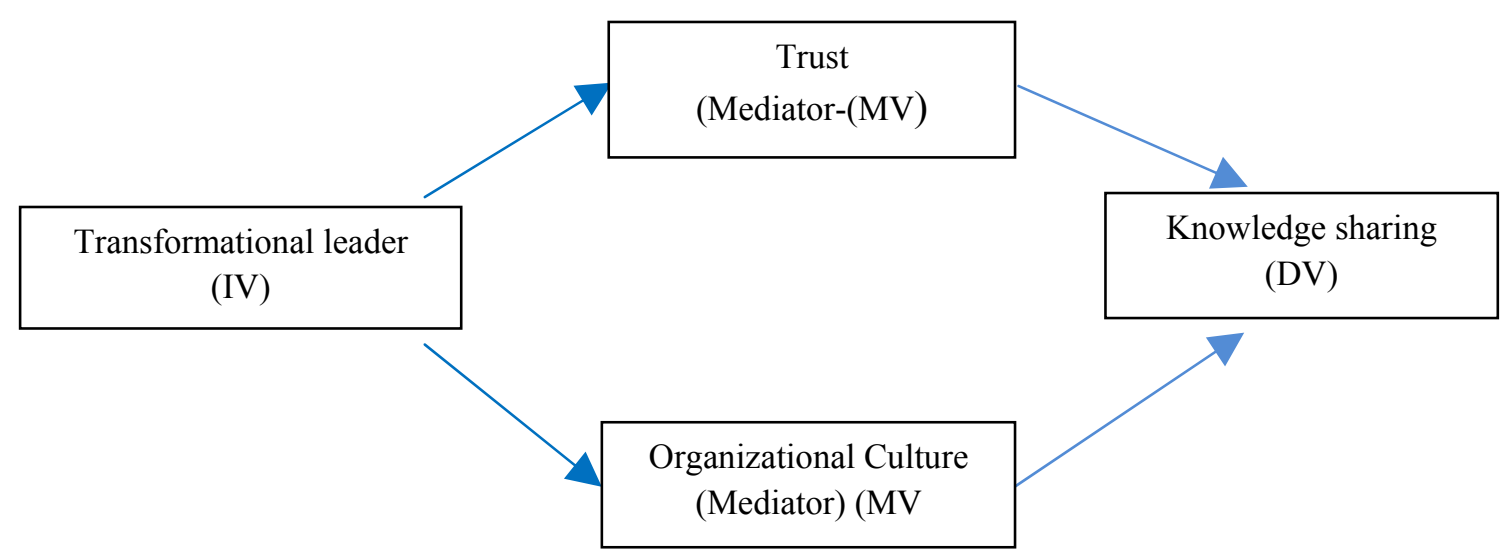

Figure 1. The theoretical framework of the present study

\section{Research Questions and Hypotheses}

What is the original problem this question must be first addressed? The precise research questions that are related to the objectives and purposes are further divided into the following diverse but related portions, articulated here as:

1. What is the nature of relationships that exists between transformational leader and knowledge sharing in public sector hospitals?

2. How do knowledge sharing enhances through organizational culture and trust sharing in public sector hospitals?

3. How does service quality enhance through knowledge sharing in public sector hospitals? 
Eight hypotheses were developed for measuring the mediating role of trust and organizational culture:

$\mathbf{H}_{1}$ : Transformational leader is significantly related with Trust.

$\mathbf{H}_{2}$ : Trust is significantly related with knowledge sharing.

$\mathbf{H}_{3}$ : Transformational leader is significantly related with knowledge sharing.

$\mathbf{H}_{4}$ : Trust plays mediating role in the relationship between Transformational leader and knowledge sharing.

$\mathbf{H}_{5}$ : Transformational leader is significantly related with organizational culture.

$\mathbf{H}_{6}$ : Organizational culture is significantly related with knowledge sharing.

$\mathbf{H}_{7}$ : Transformational leader is significantly related with knowledge sharing.

$\mathbf{H}_{\mathbf{8}}$ : Organizational culture plays mediating role in the relationship between transformational leader and knowledge sharing.

\section{Method}

An extensive review of the literature indicates the researcher's ontology and epistemology based on any paradigm in business and management studies (i.e. Positivist, Interpretive, and Realism) to explore any phenomena. These philosophical paradigms oppose each other and have their own advantages and disadvantages. The positivists believe that there is one reality in a rational, quantifiable world whereas interpretive believe feeling and emotions cannot be quantifiable and every individual has its own interpretation of reality.

For the purpose of this research, positivist philosophical paradigm is appropriate and research approach was deductive approach. However, examination of substantive and theoretical perspective of transformational leader, knowledge sharing delivers a resilient backing for the quantitative technique as the most prolific investigation method. Furthermore, the positivist research philosophy was used and research approach was deductive. Following this, the data collection method was survey based. The reason beyond using positivist philosophy is that the research is based on quantifiable and measurable phenomena.

The unit of analysis practiced in the current study is the healthcare sector which is a service organization particularly Public Sector Hospitals; where, a service organization is involved in the distribution of one or more offerings that are not perceptible goods. The intention here is to make a distinction between organizations for which the intangible component of their activities is a substantial part of the total offering. The reason for choosing Public Sector Hospitals is that performance of the Public Sector Hospitals is lacking behind as compared to Private Sector Hospitals and Public Sector Hospitals do not give due importance to their valuable knowledge. The data was collected by using structured research instrument and then subsequently derived information was used to answer the research questions. Likert scale was employed to analyse the psychometric analysis of respondent's behavior (Likert, 1967). In order to attain face and content validity, draft of questionnaire was checked by four academicians, six scholars, and four expert practitioners. From their responses several items were discarded and modified. Self-administered questionnaires were distributed to variety of hospital for pilot testing to collect the data from both genders of diverse age groups and demographics.

A pilot test was carried out to measure the content validity of the questionnaire and entire items fulfilled the required criteria (e. g. 0.75); to this end, transformational leader, 
organizational culture, trust, and knowledge sharing were $0.83,0.78,0.75$, and 0.76 , respectively.

The sampling frame used in this survey was based on a listing maintained by health sector of Pakistan. From this sampling frame the selection of potential respondent hospitals was undertaken on convenient basis. The purpose of probability sampling is to generalize the results of the sample population to the population of interest.

As a first step, simple random sampling was used. Nurses, doctors, and paramedical was the sampling frame for this study. As a second step, stratified sampling was applied and the sampling frame was separated into different strata i.e. gender and age. Finally, data was collected from each stratum randomly. The first strata were of 20-30 age groups and the second stratum was 31-40 age groups. Then, the third stratum and the last stratum were 41-50 and 5160 age groups, respectively. As a third step, data was divided into two more strata that were qualification (Bachelors, Masters, BSCN, and MBBS) and designation (top, middle, and lower).

The sample size consisted of 6 hospitals with the 100 respondents. The number of doctors, nurses, and paramedical staff was sampled from each hospital which is sufficiently large and provides stability in the responses and in their perceptions. Consistent with the Bayesian approach no predetermined sample size was imposed.

\section{Results}

\section{Descriptive Analysis}

Questionnaires were filled by self-administration. The demographic data shows that $60 \%$ were male and 40\% were female. Approximately 11\% had Higher Graduate diploma, 40\% held Bachelor degree, and 49\% had Master's degree. All the three categories of designations were involved; to this end, $10 \%$ were related to top management, $70 \%$ were related to middle management, and 20\% were related to lower management. An aggregate of $20 \%$ were represented 0 to 5 years' experience, $30 \%$ had 6 to 10 years' experience, and $50 \%$ hade above 10 years' experience. Moreover, 50\% belonged to 20 to 30 age group, $30 \%$ belonged to 31 to 40 age group, and $20 \%$ belonged to 41 to 50 age group.

\section{Factor Analysis}

The objective of utilizing factor analysis is to examine the associations among inter-level variables that is available in large quantity. To measure factor loading, principle component analysis technique was applied. The items that have below 0.40 value were discarded and not used any more. Kaiser-Meyer-Olkin (KMO) is used to measure the sample appropriateness. The purpose of KMO is to demonstrate how much the items are sufficient for the respective factor. The values of KMO and Bartlett meet the required criteria. For example, 0.65 for KMO and 0.05 for Bartlett depicts that both are significant. 


\section{Correlation}

Table 1 shows the correlation matrix which demonstrates the correlation results. The sign** depicts high correlation between variables at 0.01 level of significance and the sign * depicts high correlation between variables at 0.05 .

Table 1

Correlation Matrix

\begin{tabular}{ccccc}
\hline & TL & Trust & OC & KS \\
\hline TL & 1 & & & \\
Trust & -0.01 & 1 & & \\
OC & $0.31^{* *}$ & $-0.31^{* *}$ & 1 & 1 \\
KS & $0.20^{*}$ & -0.15 & $0.26^{* *}$ & 1 \\
\hline
\end{tabular}

** Correlation is significant at the 0.01 level (2-tailed).

* Correlation is significant at the 0.05 level (2-tailed).

\section{Regression Analysis}

Four steps of Multiple Regressions analysis as recommended by Baron \& Kenny (1986) was adopted in the current research for analysis and interpretation of hypothesis to assess the mediating role of variables, 'trust and organizational culture', between 'transformational leadership' and 'knowledge sharing'. The method was already utilized in many previous management research. Following the recommended method, four steps of regression analysis were applied to examine/measure the effect of mediating variable. Therefore, to establish the mediation of mediating variable, three assumptions were tested.

\section{Procedure I}

There are two mediating variables including trust and organizational culture. For measuring the mediation of both variables Baron \& Kenny (1986) was applied. The mediation of trust was measured and three steps of regressions were used. Firstly, dependent variable (knowledge sharing) was regressed on independent variable (transformational leader). Secondly, mediating variable (trust) was regressed on independent variable (transformational leader). Thirdly, dependent variable (Knowledge sharing) was regressed on mediating variable (trust). Since, these results indicate the meeting of assumptions, dependent variable (transformational leader) was regressed on both the mediating variable (trust) and independent variable (transformational leader). The following section summarizes the findings which depicts that trust plays a significant but partial mediating role between relationship of transformational leader and knowledge sharing.

Step 1: Carry out a simple regression analysis along with IV anticipating DV $\mathrm{IV} \longrightarrow \mathrm{DV}, \mathrm{TL}-\mathrm{KS}$

Knowledge sharing $(\mathrm{KS})=\beta_{0}+\beta_{1} *$ Transformational leader (TL) $+e$

Step 2: Carry out a simple regression analysis along with IV anticipating MV

$\mathrm{IV} \longrightarrow \mathrm{MV}$, TL-Trust

Trust $=\beta_{0}+\beta_{1} *$ Transformational leader (TL) $+e$ 
Step 3: Carry out a simple regression analysis along with MV anticipating DV $\mathrm{MV} \rightarrow \mathrm{DV}$, Trust-KS

Knowledge sharing $(\mathrm{KS})=\beta_{0}+\beta_{1} *$ Trust $+e$

Step 4: Carry out a multiple regression analysis along with IV and MV anticipating DV $\mathrm{IV} \longrightarrow \mathrm{MV} \longrightarrow \mathrm{DV}, \mathrm{TL} \&$ Trust-KS

Knowledge sharing $(\mathrm{KS})=\beta_{0}+\beta_{1} *$ Transformational leader $+\beta_{2} *$ Trust $+e$

\section{Procedure II}

The mediation of organizational culture was measured and again three steps of regression were measured. Firstly, dependent variable (knowledge sharing) is regressed on independent variable (transformational leader). Secondly, mediating variable (organizational culture) is regressed on independent variable (transformational leader). Thirdly, dependent variable (knowledge sharing) was regressed on mediating variable (trust). Since, these result indicate the meeting of assumptions, dependent variable (transformational leader) was regressed on both the mediating variable (organizational culture) and independent variable (transformational leader). The following part summarizes the findings which depicts that organizational culture plays a significant but partial mediating role between relationship of transformational leader and knowledge sharing.

Step 1: Carry out a simple regression analysis along with IV anticipating DV $\mathrm{X} \rightarrow \mathrm{Y}, \mathrm{TL}-\mathrm{KS}$

Knowledge sharing $(\mathrm{KS})=\beta_{0}+\beta_{1} *$ Transformational leader (TL) $+e$

Step 2: Carry out a simple regression analysis along with IV anticipating $M V$ $\mathrm{X} \rightarrow \mathrm{M}, \mathrm{OC}-\mathrm{TL}$

Organizational culture $(\mathrm{OC})=\beta_{0}+\beta_{1} *$ Transformational leader $(\mathrm{TL})+e$

Step 3: Carry out a simple regression analysis along with MV anticipating DV $\mathrm{M} \longrightarrow \mathrm{Y}, \mathrm{KS}-\mathrm{OC}$

Knowledge sharing $(\mathrm{KS})=\beta_{0}+\beta_{1} *$ Organizational culture $(\mathrm{OC})+e$

Step 4: Carry out a simple regression analysis along with IV and MV anticipating DV $\mathrm{X} \longrightarrow \mathrm{M} \longrightarrow \mathrm{Y}, \mathrm{TL} \& \mathrm{OC}-\mathrm{KS}$

Knowledge sharing $(\mathrm{KS})=\beta_{0}+\beta_{1} *$ Transformational leader $+\beta_{2} *$ Organizational culture $(\mathrm{OC})+e$

Table 2 represents the regression analysis. 
Table 2

Regression Analysis

\begin{tabular}{|c|c|c|c|c|c|c|c|}
\hline \multirow{2}{*}{ Hypothesis } & \multicolumn{2}{|c|}{ Association } & \multicolumn{2}{|c|}{ ANOVA } & \multirow[b]{2}{*}{$\mathrm{t}$} & \multirow[b]{2}{*}{ B } & \multirow{2}{*}{ Accepted/Rejectec } \\
\hline & & & Adjusted $\mathrm{R}^{2}$ & $\mathrm{~F}$ & & & \\
\hline H1 & TL & KS & 0.03 & 4.35 & 2.08 & 0.20 & Accepted \\
\hline $\mathrm{H} 2$ & $\mathrm{TL}$ & Trust & -0.0 & 0.03 & -0.18 & -0.01 & Rejected \\
\hline $\mathrm{H} 3$ & Trust & KS & 0.01 & 2.38 & -1.54 & -0.15 & Accepted \\
\hline \multirow{2}{*}{$\mathrm{H} 4$} & $\mathrm{TL}$ & \multirow{2}{*}{$\mathrm{KS}$} & \multirow{2}{*}{0.04} & 3.37 & 2.07 & 0.20 & Accepted \\
\hline & Trust & & & & 1.52 & -0.15 & Rejected \\
\hline H5 & TL & KS & 0.03 & 4.35 & 2.08 & 0.20 & Accepted \\
\hline H6 & $\mathrm{OC}$ & TL & 0.08 & 10.66 & 3.26 & 0.31 & Accepted \\
\hline $\mathrm{H} 7$ & KS & $\mathrm{OC}$ & 0.06 & 7.30 & 2.70 & 0.26 & Accepted \\
\hline \multirow{2}{*}{ H8 } & TL & \multirow{2}{*}{$\mathrm{KS}$} & \multirow{2}{*}{0.06} & 4.58 & 1.34 & 0.18 & Rejected \\
\hline & $\mathrm{OC}$ & & & & 2.15 & 0.22 & Accepted \\
\hline
\end{tabular}

$\mathrm{P}<0.001, * \mathrm{P}<0.05, * * \mathrm{P}<0.01$

\section{Discussion and Conclusion}

The current study facilitates filling the knowledge gap that is prevailing in such specified field; specifically, in Pakistan none of the empirical research was conducted on that particular topic. The scrutinization of the current study ensures numerous thought-provoking inferences for research, education, and business. The current study facilitates increasing the functioning and operations of public sector hospitals in Pakistan. The vital role of the current study is that questionnaire was developed which deals with the notions and that is backed by suitable values of reliability and validity from expert practitioners, scholars, and academicians.

The outcomes of the present study also imply that health care sector should develop an organizational culture where transformational leaders give importance to their organizational knowledge for the amplification of their performance. The support and encouragement, both tangible and intangible, are anticipated from the doctors and paramedical staff to share their valuable knowledge for augmenting organizational performance.

The present study tries to find out the relationship of transformational leader along with organizational culture and trust in creating knowledge sharing among organizational members that in turns heighten performance. The results of the current study are quite reasonable; however, the deficiency of time prevents us from demonstrating more across-the-board inferences. The current study is also helpful from administrative standpoint since doctors, nurses, and practitioners will understand the factors that play significant part in raising knowledge sharing.

The present study is focal when seen in connection to today's amazingly aggressive environment where external and internal pressures forces the organizations to fulfill the several demands and this is one of the challenging task. Organizations should work in cooperation of both the internal and external forces to accomplish a special objective. The current study is helpful for the hospitals to know the importance of transformational leader in improving knowledge sharing. 
The significance of the current study is the consequence of the life-threatening problem that is fronted by not just limited hospitals, but whole health sector and certainly nations all together. There is utmost necessity to inspect the role of transformational leader in enhancing individual knowledge and group knowledge and how it facilitates raising service quality and this need provides the rationale for this.

\section{References}

Allee, V. (1997). The knowledge evolution: Expanding organizational intelligence. Boston: Butterworth-Heinemann.

Andaleeb, S. S. (2000). Public and private hospitals in Bangladesh: Service quality and predictors of hospital choice. Health Policy \& Planning, 15(1), 95-102.

Andaleeb, S. S. (2001). Service quality perceptions and patient satisfaction: A study of hospitals in a developing country. Social Science \& Medicine, 52(9), 1359-1370.

Ardichvili, A., Page, V., \&Wentling, T. (2003). Motivation and barriers to participation in virtual knowledge-sharing communities of practice. Journal of Knowledge Management, 7(1), 64-77.

Argote, L., Ingram, P., Levine, J. M., \& Moreland, R. L. (2000). Knowledge transfer in Organizations: Learning from the experience of others. Organizational Behaviour \& Human Decision Processes, 82(1), 1-8.

Avolio, B. J., Bass, B. M., \& Jung, D. I. (1999). Re-examining the components of transformational and transactional leadership using the Multifactor Leadership. Journal of Occupational \& Organizational Psychology, 72(4), 441-462.

Avolio, B. J., \& Bass, B. M. (2002). Developing Potential across a full range of leadership cases on transactional and transformational leadership. Mahwah, NJ: Lawrence Erlbaum Associates.

Baron, R. M., \& Kenny, D. A. (1986). The moderator-mediator variable distinction in social psychological research: Conceptual, strategic and statistical considerations. Journal of Personality Social Psychology, 51, 1173-1182.

Bass, B. M. (1985). Leadership and performance beyond expectations. New York: The Free Press.

Bass, B. M. (1999). Two decades of research and development in transformational leadership. European Journal of Work \& Organizational Psychology, 8(1), 9-32.

Bass, B. M., \&Avolio, B. J. (1994). Improving organizational effectiveness through transformational leadership. Thousand Oaks, CA: Sage Publications.

Bass, B. M., \&Riggio, R. E. (2006). Transformational leadership. Mahwah, NJ: ErlbaumLawrence Erlbaum Associates.

Bate, S. P., \& Robert, G. (2002). Knowledge management and communities of practice in the private sector: Lessons for modernizing the National Health Service in England and Wales. Public Administration, 80(4), 643-663.

Berson, Y., \&Avolio, B. J. (2004). Transformational leadership and the dissemination of organizational goals: A case study of a telecommunication firm. The Leadership Quarterly, 15(5), 625-646.

Benevene, P., \&Cortini, M. (2010). Interaction between structural capital and human capital in Italian NPOs. Journal of Intellectual Capital, 11(2), 123-139.

Beugré, C. D., Acar, W., \& Braun, W. (2006). Transformational leadership in organizations: An environment-induced model. International Journal of Manpower, 27(1), 52-62.

Birasnav, M., Rangnekar, S., \&Dalpati, A. (2011). Transformational leadership and human capital benefits: The role of knowledge management. Leadership \& Organization Development Journal, 32(2), 106-126.

Bounfour, A., \&Edvinsson, L. (2005). Intellectual capital for communities: Nations, regions, and cities. Oxford, ButterworthHeinemann.

Bryant, S. E. (2003). The role of transformational and transactional leadership in creating, sharing and exploiting organizational knowledge. Journal of Leadership \& Organizational Studies, 9(4), 32-44.

Burns, J. M. (1978). Leadership. New York: Harper \& Row.

Cassels, A. (1995). Health sector reform: Key issues in less developed countries. Journalof International development, 7(3), 329-347.

Cialdini, R. B., Petrova, P. K., Goldstein, N. J., \& Team, L. Y. (2004). The hidden costs of organizational dishonesty. MIT Sloan Management Review, 45(3), 67-73. 
Chen, L. Y. (2004). Examining the effect of organization culture and leadership behaviours on organizational commitment, job satisfaction, and job performance at small and middle-sized firms of Taiwan. Journal of American Academy of Business, $5(1 / 2), 432-438$.

Chen, C. J., \& Huang, J. W. (2007). How organizational climate and structure affect knowledge management- The social interaction perspective. International Journal of Information Management, 24(2), 104-118.

Choy, S., Lee, W., Cheung, C., \& Shim, G. (2005). Development of a knowledge management culture assessment tool with applications in aviation industry. Journal of Information \& Knowledge Management, 4(3), 179-189.

Cronin, J. J., \& Taylor, S. A. (1992). Measuring service quality: A reexamination and extension. The Journal of Marketing, $56(3), 55-68$.

Davies, H. T., Nutley, S. M., \&Mannion, R. (2000). Organizational culture and quality of health care. Quality in Health Care, 9(2), 111-119.

Denison, D. (1990). Corporate culture and organizational effectiveness. New York, NY: John Wiley \& Sons.

Denison, D. R. (1996). What is the difference between organizational culture and organizational climate? A native's point of view on a decade of paradigm wars. The Academy of Management Review, 21(3), 619-654

Dhanaraj, C., Lyles, M. A., Steensma, H. K., \&Tihanyi, L. (2004). Managing tacit and explicit knowledge transfer in IJVs: The role of relational embeddedness and the impact on performance. Journal of International Business Studies, 35(5), $428-442$.

Dixon, N. M. (2000). Common knowledge: How companies thrive by sharing what they know. Boston, MA: Harvard Business School Press.

Duygulu, S., \&Kublay, G. (2011). Transformational leadership training programmed for charge nurses. Journal of Advanced Nursing, 67(3), 633-642.

Edvinsson, L., \& Sullivan, P. (1996). Developing a model for managing intellectual capital. European Management Journal, $14(4), 356-364$

Eisenbach, R., Watson, K., \& Pillai, R. (1999). Transformational leadership in the context of organizational change. Journal of Organizational Change Management, 12(2), 80-89.

Ferlie, E. B., \&Shortell, S. M. (2001). Improving the quality of health care in the United Kingdom and the United States: A framework for change. Milbank Quarterly, 79(2), 281-315.

Fletcher, A., Guthrie, J., Steane, P., Roos, G., \& Pike, S. (2003). Mapping stakeholder perceptions for a third sector organization. Journal of Intellectual Capital, 4(4), 505-527.

Ford, D. P. (2003). Trust and knowledge management: The seeds of success. In C. W. Holsapple (Ed.), Handbook on knowledge management (pp. 553-575). Heilderberg: Springer.

Gressgård, L. J. (2011). Virtual team collaboration and innovation in organizations. Team Performance Management, 17(1/2), $102-119$.

Habersam, M., \&Piber, M. (2003). Exploring intellectual capital in hospitals: Two qualitative case studies in Italy and Austria. European Accounting Review, 12(4), 753-779.

Haas, M. R., \& Hansen, M. T. (2007). Different knowledge, different benefits: toward a productivity perspective on knowledge sharing in organizations. Strategic Management Journal, 28(11), 1133-1153.

Hendriks, P. (1999). Why share knowledge? The influence of ICT on the motivation for knowledge sharing. Knowledge \& Process Management, 6(2), 91-100.

Hussi, T. (2004). Reconfiguring knowledge management-combining intellectual capital, intangible assets and knowledge creation. Journal of Knowledge Management, 8(2), 36-52.

Jabnoun, N., \&Rasasi, A. J. A. (2005). Transformational leadership and service quality in UAE hospitals. Managing Service Quality, 15(1), 70-81.

Kenagy, J. W., Berwick, D. M., \& Shore, M. F. (1999). Service quality in health care. JAMA: The Journal of the American Medical Association, 281(7), 661-665.

Lam, S. S. (1997). SERVQUAL: A tool for measuring patients' opinions of hospital service quality in Hong Kong. Total Quality Management, 8(4), 145-152.

Lee, P., Gillespie, N., Mann, L., \& Wearing, A. (2010). Leadership and trust: Their effect on knowledge sharing and team performance. Management Learning, 41(4), 473-491.

Mahmood, S., \& Ali, B. (2011). An empirical investigation on knowledge workers productivity in telecom sector of Pakistan. Information Management \& Business Review, 3(1), 27-38. 
Malhotra, Y. (2002). Why knowledge management systems fail? Enablers and constraints of knowledge management in human enterprises.In C. W. Holsapple (Ed.), Handbook on knowledge management 1: Knowledge matters (pp. 577-599). Heidelberg, Germany: Springer-Verlag.

Middleton, J (2002). Culture. Oxford: London

Munir, F., Nielsen, K., Garde, A. H., Albertsen, K., \&Carneiro, I. G. (2012). Mediating the effects of work-life conflict between transformational leadership and health-care workers' job satisfaction and psychological wellbeing. Journal of Nursing Management, 20(4), 512-521.

Olson, J. R., Belohlav, J. A., Cook, L. S., \& Hays, J. M. (2008). Examining quality improvement programs: The case of Minnesota hospitals. Health Services Research, 43(5), 1787-1806.

Orr, J. E. (1990). Sharing knowledge, celebrating identity: Community memory in a service culture. In D. S. Middleton, \& D. Edwards (Eds.),Collective remembering: Memoryin society,(pp.169-189). Beverly Hills, CA: Sage.

Oreg, S., \&Berson, Y. (2011). Leadership and employees' reactions to change: the role of leaders personal attributes and transformational leadership style. Personnel Psychology, 64(3), 627-659.

Peng, T. J. A., Pike, S., \&Roos, G. (2007). Intellectual capital and performance indicators: Taiwanese healthcare sector. Journal of Intellectual Capital, 8(3), 538-556.

Politis, J. D. (2001). The relationship of various leadership styles to knowledge management. Leadership \& Organization Development Journal, 22(8), 354-364.

Renzl, B. (2008). Trust in management and knowledge sharing: The mediating effects of fear and knowledge documentation. Omega, 36(2), 206-220.

Ribière, V. M., Sitar A. (2003). Critical role of leadership in nurturing a knowledge-supporting culture. Knowledge Management Research \& Practice, 1(1), 39-48.

Rosenthal, M. B., \& Frank, R. G. (2006). What is the empirical basis for paying for quality in health care? Medical Care Research \& Review, 63(2), 135-157.

Savage, C.M. (1996). Fifth generation management: Co-creating through virtual enterprising, dynamic teaming, and knowledge networking ( $\left.2^{\text {nd }} e d\right)$. Boston, Massachusetts: Butterworth-Heinemann.

Saint-Onge, H. (1996). Tacit knowledge the key to the strategic alignment of intellectual capital. Strategy \& Leadership, 24(2), $10-16$.

Scotti, D. J., Harmon, J., \&Behson, S. J. (2006). Links among high-performance work environment, service quality, and customer satisfaction: an extension to the healthcare sector. Journal of Healthcare Management/American College of Healthcare Executives, 52(2), 109-124.

Scott, P. B. (2005). Knowledge workers: Social, task and semantic network analysis. Corporate Communications: An International Journal, 10(3), 257-277.

Shamir, B., House, R. J., \& Arthur, M. B. (1993). The motivational effects of charismatic leadership: A self-concept based theory. Organization Science, 4(4), 577-594.

Shaikh, B. T., \& Hatcher, J. (2005). Health seeking behaviour and health service utilization in Pakistan: challenging the policy makers. Journal of Public Health, 27(1), 49-54. 